\title{
Leakage monitoring research and design for natural gas pipelines based on
}

\section{dynamic pressure waves}

\author{
Cuiwei Liu $^{\mathrm{a}, \mathrm{b}, \mathrm{c}}$, Yuxing ${ }^{1} \mathrm{Li}^{\mathrm{a}, \mathrm{b}, \mathrm{c}}$
}

(a. College of Pipeline and Civil Engineering in China University of Petroleum (East China), Qingdao 266580; b. Key laboratory of Qingdao oil and gas storage and transportation technologies, China; c. Key laboratory of CNPC heavy gas transportation and LNG technologies, China)

Abstract: Many types of gases, such as natural gas, hydrogen, and so on, are transported via pipelines using a chemical process, though leakages in these pipelines create waste and pose hazards and risks to industries, the environment and people. To monitor gas pipelines, a new leak detection and location method based on the amplitude attenuation model of dynamic pressure waves was designed and researched by experiments, compared with traditional method based on the propagation velocity and time differences as determined by the waveforms of the upstream and downstream signals. Both methods are achieved based on the propagation law of the dynamic pressure waves in the fluid flow. First, the fundamentals of the newly proposed method are clarified by considering the influence of gas flow on the waves. The experiments are then conducted in gas pipelines with $42 \mathrm{~mm}$ internal diameters. Finally, the results of the experiments are discussed and analyzed. The results indicate that all leakages can be detected by both methods but that the largest location error of the traditional method is $-0.780 \%$, whereas the largest location errors with respect to the new method are $0.054 \%$ with the experimental attenuation coefficients and $2.055 \%$ with the theoretical attenuation coefficients. It is further determined that the influence of the gas flow effects cannot be ignored by either method. Accordingly, the conclusions drawn suggest that the proposed methods can be applied to monitor gas pipelines.

Keywords: leakage monitoring; gas pipelines; dynamic pressure wave; gas flowing effect; experiments 


\section{Introduction}

With the rapid development of the pipeline industry, chemical gases, such as natural gas, hydrogen, etc., are being transported via pipelines, and thus, leakages in these pipelines occur occasionally that pose hazards and risks to the environment and the people. Taking into account that natural gas availability is not inexhaustible, its cost is extremely high. Therefore, to monitor pipelines, many leak detection and location methods ${ }^{[1]}$ have been developed. For example, Alkhaledi ${ }^{[2]}$ used the fault tree analysis to identify the source of leaking gas, and the results serve as a useful reference if any similar gas leak incidents occur elsewhere. Elaoud ${ }^{[3]}$ presented a technique using transient negative pressure waves initiated by the sudden closure of a downstream shut-off valve. The presence of a leak in a pipe partially reflects these pressure waves and allows for the location of the leak. Scott ${ }^{[4]}$ employed a method based on a real-time transient model that can detect small leaks, albeit it has the disadvantage of being very expensive. Moreover, as the models employed are complex, they require a trained user. Doothy ${ }^{[5]}$ proposed a real-time pipeline leak detection method that incorporates volume balancing to detect and locate small leaks. However, if small leaks occur, it takes considerable time to detect them, and furthermore, Doothy's system is prone to false alarms during transient states unless thresholds are adapted. Zhang ${ }^{[6]}$ proposed a novel hybrid technique for leak detection and location based on a real-time transient modeling method combined with a negative pressure wave method. The results of the experiments indicated that Zhang's hybrid technique successfully detects and locates gas pipeline leaks.

To describe the methods, the evaluation indexes are clarified as follows. (1) Sensitivity refers to the smallest leakage rate that can be detected. (2) Location accuracy equals the absolute differential value divided by the pipeline length, which equals the located leakage point minus the actual leakage point. (3) False alarms are those alerts that occur when there is no leakage. (4) Missing alarms refer to the failure of alarms to alert when a leakage does occur. (5) Detection time is the time the method takes to detect and locate the leakage point. (6) Cost is the money spent for facilities and 
maintenance charges. For each index, a score of 0 is awarded to the worst method, and a score of 5 is awarded to the best method, i.e., the larger the score, the better the method.

According to the evaluation indexes, the usual methods identified above including the acoustic method are presented in Table 1.

From among the presented methods, the acoustic method is found to be more promising. Lee ${ }^{[7]}$ established an oil and gas pipeline failure prediction system using long range ultrasonic transducers (LRUT) and a Euclidean-support vector machine (E-SVM) classification approach. The results indicate that the E-SVM approach is ideally suited for classifying data from pipelines. Yan ${ }^{[8]}$ proposed the gas leak detection technology of the spacecraft in orbit based on an acoustic sensor array. The detection distance and direction of the array are verified by the experiments. The method based on the dynamic pressure wave is one type of acoustic method that uses dynamic pressure sensors, where the acoustic waves measured by the dynamic pressure sensors have a wide frequency range of which the low frequency component can spread over a long distance. Thus, due to its advantages, it has been researched increasingly more frequently.

The key aspect of a leak detection system based on an acoustic method is the ability to extract the effective characteristics from the measured signals. Currently, the main filtering methods are based on time domain and frequency domain analyses, though the blind source separation method has also been studied. Yan ${ }^{[9]}$ proposed an improved algorithm of median filtering based on extremum detection, and the results indicate that the proposed algorithm is superior to traditional ones with respect to noise removal and edge retention. $\mathrm{Xu}^{[10]}$ proposed a de-noising algorithm via Wiener filtering in the shearlet domain and found that the combination removes noises more effectively than other methods. $\mathrm{Hu}^{[11]}$ proposed a new signal extracting method that combines a wavelet de-noising technique and the short-time Fourier transform method. The feasibility and accuracy of Hu's proposed method are verified by numerical simulation and practical experiments. Mostafapour ${ }^{[12]}$ proposed a combination method of wavelet transform and a cross-time frequency spectrum to 
process signals. The resulting locating error indicates high precision of the proposed algorithm. Lu ${ }^{[13]}$ applied fast independent component analysis (FastICA) to measure non-Gaussian independent components in blasting vibration signals as the approximation signals were separated, and the results indicate that the approximation signal close to the source signal can be precisely separated using the

FastICA approach. $\mathrm{Ni}^{[14]}$ proposed the combination of a wavelet packet and information entropy and the combination of empirical mode decomposition and information entropy. Under the condition of high noises, the proposed method is applied better. Sun ${ }^{[15]}$ proposed a leak aperture recognition and location method based on the root mean square entropy of a local mean deposition and Wigner-Ville time-frequency analysis. The results indicate that the method can effectively identify different leak apertures and that the leak location accuracy is better than that of other methods. Liu ${ }^{[16]}$ conducted the time-frequency analysis of the acoustic leakage signal measured by dynamic pressure sensors based on the Hilbert-Huang transform, and the results found that effective characteristics of dynamic pressure waves can be extracted.

After the leakage characteristics are extracted, they are applied to locate the leak, a task for which the time differences and velocities are important. Ye ${ }^{[17]}$ developed an analytical model to predict the cross correlation function of leak signals in plastic water pipes, which can be used to calculate the time difference and improve leak location accuracy. Brennan ${ }^{[18]}$ presented a new interpretation of the process of cross-correlation for time delay estimation and found that time delay estimations and their variances calculated using time and frequency domain methods are almost identical. Meng ${ }^{[19]}$ established a formula using dynamic pressure waves to determine the locations of gas pipeline leaks. Meng's formula can be modified based on the influences of temperature and pressure. Liu ${ }^{[20]}$ established a generation model of dynamic pressure waves to extract precise time differences and improve leak location accuracy.

Most of the extant studies have been conducted to improve the accuracy of velocity and time differences according to which the method is called the traditional leak location method. A dynamic 
100 pressure wave is generated, transmitted through fluid and acquired by sensors that are installed at 101 both ends of the pipeline. It is then processed to extract specific characteristics to determine whether 102 a leak has occurred and to calculate the time differences to locate the leak. Once leakage occurs, the 103 computer sends out alarms and locates the leakage if accurate velocity and synchronized timing 104 measurements can be achieved. However, it is difficult to confirm velocity due to different pressures and temperatures. Thus, velocity calculation requires more pressure and temperature sensors, especially for gas pipelines. Furthermore, if the method is applied to field or long distance pipelines, the time difference calculation requires the data be well synchronized, as presented in Fig. 1. Fig. 1 indicates that the variation in reporting times from one data acquisition device (DAD) to the computer can be quite large. Because the time-stamping is usually not performed at the level of the DAD but rather at the centralized computer level, this procedure yields uncertainty regarding the age of data that are collected in computer. This issue is also discussed by Magnis and Petit ${ }^{[21]}$ as they considered the importance of data synchronization with respect to loss detection. They noted that the data should be carefully time-stamped with accurate and synchronized clocks, e.g., GPS or Rugby clocks, though they are not readily available and are subject to jamming in many areas. Unfortunately, these recommendations are far from optimal technical status observed in currently installed systems.

116 Petit $^{[22]}$ analyzed problems induced by the imprecise dating of measurements, especially the 117 mis-synchronization in oil and gas production. The results reveal that when signals with significant 118 time variations are monitored, the impact of the dating of measurements can be troublesome or even 119 worse than measurement noises. Accordingly, the above analyses suggest that the time difference 120 calculation is a problem in the application of the acoustic method. Based on this perspective, the 121 method without velocity and time differences can be considered to be more concise and easier. Thus, 122 Liu $^{[23]}$ proposed a method based on amplitude, for which the propagation law is researched. When a 123 leak location approach is conducted, the errors are large, i.e., greater than $1 \%$, primarily because 124 when the propagation law is researched, the gas flowing effect is neglected and the scale of the 
wavelet transform method is so large that the amplitude loss is large.

Meanwhile, a group of scholars conducted studies on the propagation characteristics of acoustic waves. Hunaidi ${ }^{[2]}$ conducted experiments using plastic water pipes and found that the amplitude of the signals attenuate with the propagation distance at a speed of $0.25 \mathrm{~dB} / \mathrm{m}$. Muggleton ${ }^{[25]}$ analyzed

129 the mechanism of propagation behavior of sound and vibration waves and established the 130 propagation model of signals. Liu ${ }^{[26]}$ studied the attenuation characteristics of the wave of a 131 fluid-filled pipeline and concluded that longitudinal waves attenuate more slowly in the pipeline.

132 However, the studies on the attenuation model are insufficient.

133 In this paper, the propagation model of dynamic pressure waves considering the influence of the gas 134 flowing effect will be studied. Then, based on the established model, the location method, which

\section{Materials and methods}

\subsection{Methods of leak detection and location based on amplitude}

Leak detection should be first accomplished, as in Fig. 2(a), by processing the measured signals to acquire $p_{n 1}, p_{n 2}(\mathrm{kPa})$. If any one of $p_{n 1} / p_{A 0} \geq p_{A} / p_{A 0}, p_{n 2} / p_{A 0} \geq p_{A} / p_{A 0}$ is satisfied, a leak exists. In the formula, $p_{A 0}(\mathrm{kPa})$ is the reference pressure and $p_{A} / p_{A 0}$ is the threshold value, both of which can be obtained using the test experiment with the smallest leakage orifice, as in Fig. 2(b). When leakage occurs at one end, the acoustic waves are measured at two ends; $p_{A 0}$ is the one measured at the same end, which can be calculated using the aero-acoustics theory ${ }^{[20][27]}$. All of the amplitudes are acquired through the wavelet transform (WT) method ${ }^{[28][29]}$.

To verify the WT method, the actual signals of field pipelines are measured. The first dynamic pressure sensor is located downstream $65 \mathrm{~cm}$ away from the leakage point, and the other is installed $20 \mathrm{~km}$ away. The signals are measured at $1000 \mathrm{~Hz}$. The energy of leakage signals is mainly 
concentrated at $0 \sim 50 \mathrm{~Hz}$. With respect to the WT, the relationship between the sampling rate $S R(\mathrm{~Hz})$

150 and the scale $s$ is:

$$
S R / 2^{s+1} \leq 50
$$

152 With a scale of 4 , the sub-band frequency range is $0 \sim 31.25 \mathrm{~Hz}$. The characteristics of the WT

153 analyses are presented in Table 2.

154 When leakage occurs, the leakage characteristics can be extracted using the WT method, which can 155 cover a long distance.

156 First, the basic equations of acoustic waves can be established ${ }^{[23][30]}$ :

$$
\frac{\partial^{2} p}{\partial t^{2}}-c_{0}^{2} \frac{\partial^{2} p}{\partial x^{2}}=0
$$

The equation of the three-dimensional acoustic wave is illustrated as follows in the

Cartesian coordinates:

$$
\frac{\partial^{2} p}{\partial t^{2}}-c_{0}^{2}\left(\frac{\partial^{2}}{\partial x^{2}}+\frac{\partial^{2}}{\partial y^{2}}+\frac{\partial^{2}}{\partial z^{2}}\right) p=0
$$

161 When the radiation is constrained within the cylindrical pipe, formula (3) can be expressed under the cylindrical coordinates as follows:

$$
\frac{1}{r} \frac{\partial}{\partial r}\left(r \frac{\partial p}{\partial r}\right)+\frac{1}{r^{2}} \frac{\partial^{2} p}{\partial \theta^{2}}+\frac{\partial^{2} p}{\partial z^{2}}=\frac{1}{c_{0}^{2}} \frac{\partial^{2} p}{\partial t^{2}}
$$

164 The equation of the plane wave is one-dimensional, and the dynamic pressure is illustrated as 165 follows:

$$
p(x, t)=p_{a} e^{j\left(\omega t-k_{0} x\right)}
$$

167 where $p_{a}(\mathrm{~Pa})$ is the amplitude of the acoustic pressure: $\omega(\mathrm{Hz})$ is the angular frequency; $168 k_{0}=\omega / c_{0}$ is the wave number of undamped waves: and $c_{0}(\mathrm{~m} / \mathrm{s})$ is the velocity of the acoustic 169 wave.

170 Thus, the pressure waves propagating in the gas pipelines can be described by equation (5), which is 
191 yields

simplified. However, in an actual situation, a dissipative process will lead to attenuation, in which a damping effect ${ }^{[31][32]}$ (including viscous absorption and heat conduction) should be considered.

The equation with the visco-thermal absorption coefficient is obtained ${ }^{[23][30]}$ as follows:

$$
p=p_{0} e^{-\alpha x} e^{j\left(\omega t-k_{0} x\right)}
$$

In equation (6), $\alpha$ is the damping absorption coefficient that describes the attenuation speed of the amplitude with the distance: $x(\mathrm{~m})$ is the propagation distance: and $p_{0}(\mathrm{~Pa})$ is the absolute amplitude value generated at the leakage point.

In addition to the visco-thermal absorption effects, the fluid flowing effects should also be considered. As a result, the basic equations of acoustic waves can be expressed as ${ }^{[33]}$ :

$$
\left[\frac{D^{2}}{D t^{2}}-c^{2} \frac{\partial^{2}}{\partial x^{2}}+2(\alpha c+\xi U) \frac{D}{D t}\right] p=0
$$

where $\xi=F / 2 D ; F=f(\operatorname{Re}) ; F$ is Froude's number, which is the function of Reynolds number;

$\operatorname{Re}=U D \rho_{0} / \mu ; \rho_{0}\left(\mathrm{~kg} / \mathrm{m}^{3}\right)$ is the gas density; $\mu(\mathrm{Pa} \cdot \mathrm{s})$ is the dynamic viscosity coefficient; $U(\mathrm{~m} / \mathrm{s})$ is the fluid velocity; $D(\mathrm{~m})$ is the diameter; and $c(\mathrm{~m} / \mathrm{s})$ is the average velocity of the acoustic wave. Equation (7) assumes the same form as equation (2) with the addition of the carrying effect term of uniform flowing and the friction term between the flow and the pressure waves. The solution form is assumed following the expression:

$$
p(x, t)=C e^{j \omega t} e^{\beta x}
$$

where $\beta$ is the exponent coefficient with which the propagating solution follows equation (8). Substituting (8) for (7) and considering

$$
M^{2} \alpha^{2}<\alpha^{2}<<k^{2}, \quad \xi^{2} M^{4}<\xi^{2} M^{2}<<k^{2}, 2 \xi M^{3} \alpha<2 \xi M \alpha<<k^{2}
$$

$$
\beta^{ \pm}=\mp\left(\frac{\alpha+\xi M+j k}{1 \pm M}\right)
$$

Therefore, the solution to equation (7) is: 
195 In the above equations, $C, C_{1}, C_{2}$ represent undetermined coefficients; $M=U / c_{0}$ is the Mach number; and $k$ is the wave number. Compared with equation (7), the amplitude attenuation of equation (11) including the distance is described by equation (12):

$$
p(x)=p_{0} \exp \left(-\frac{\alpha+\xi M}{1+M} x\right)
$$

$$
p(x)=p_{0} \exp \left(\frac{\alpha+\xi M}{1-M} x\right)
$$

It is evidenced that the amplitude attenuation law follows the exponential curve. Based on equations (12a) and (12b), the propagation principle along the pipeline is obtained, as presented in Fig. 3 .

Based on Fig. 3, two equations can be combined as follows:

$$
p(x)=p_{0} \exp \left(-\frac{\alpha+\xi M}{1 \pm M}|x|\right)
$$

The attenuation coefficients (ACs) are then expressed as:

$$
\begin{aligned}
& \alpha^{+}=\frac{\alpha+\xi M}{1+M}=\frac{\alpha(M)}{1+M} \\
& \alpha^{-}=\frac{\alpha+\xi M}{1-M}=\frac{\alpha(M)}{1-M}
\end{aligned}
$$

where $\alpha^{+}$is the attenuation coefficient when the wave propagates in the same direction as the fluid flow, while $\alpha^{-}$is the attenuation coefficient when the wave propagates in the opposite direction. $\alpha(M)=\alpha+\xi M$ represents the actual value of the attenuation coefficient in the flowing fluid and

210 includes the turbulent effect. $1 \pm M$ represent the Doppler effect resulting from the uniform flow. $\alpha$ can be obtained as follows:

$$
\alpha=\frac{1}{r c_{0}} \sqrt{\frac{\eta^{\prime} \omega}{2 \rho_{0}}}+\frac{\omega^{2}}{2 \rho_{0} c_{0}^{3}} \cdot \eta^{\prime \prime}+\frac{\omega^{2}}{2 \rho_{0} c_{0}^{3}} \cdot \chi\left(\frac{1}{c_{v}}-\frac{1}{c_{p}}\right)
$$


213 where $\chi(\mathrm{W} /(\mathrm{m} \cdot \mathrm{K}))$ denotes heat conductivity; $\eta^{\prime}(\mathrm{Pa} \cdot \mathrm{s})$ is the shear viscosity coefficient;

$214 \quad \eta^{\prime \prime}(\mathrm{Pa} \cdot \mathrm{s})$ represents volume viscosity; $c_{v}(\mathrm{~kJ} /(\mathrm{kg} \cdot \mathrm{K}))$ is the constant-volume specific heat;

$215 c_{p}(\mathrm{~kJ} /(\mathrm{kg} \cdot \mathrm{K}))$ is the constant-pressure specific heat; and $r(\mathrm{~m})$ is the inner diameter of the pipe.

216 As presented in Fig. 3, it can be concluded that

$$
\begin{aligned}
& p_{1}=p_{0} \exp \left(-\frac{\alpha+\xi M}{1-M}|x|\right) \\
& p_{2}=p_{0} \exp \left[-\frac{\alpha+\xi M}{1+M}(L-|x|)\right]
\end{aligned}
$$

219 Here, $p_{1}(\mathrm{kPa})$ is the amplitude of the signal measured by the upstream sensor, and $p_{2}(\mathrm{kPa})$ is the

220 signal measured by the downstream sensor.

221 Thus, a new leak location method is proposed:

$$
|x|=\frac{\ln \left(p_{2} / p_{1}\right)+\alpha^{+} L}{\alpha^{+}+\alpha^{-}}
$$

where $L(\mathrm{~m})$ is the distance between the two sensors. If the gas flowing velocity is so small that it can be ignored, equation (19) can be expressed as:

$$
|x|=\frac{\ln \left(p_{2} / p_{1}\right)+\alpha(M) L}{2 \alpha(M)}=\frac{L}{2}+\frac{\ln \left(p_{2} / p_{1}\right)}{2 \alpha(M)}
$$

Compared with the traditional method, the proposed method is simpler. The newly proposed method focuses on the amplitude of the pressure waves, and cares little about velocity and time difference. In the traditional method, the amplitude of the pressure waves is used to calculate the time difference,

229 while in the new method, it is used directly to locate leakages.

\section{$230 \quad 2.2$ Leak detection and location experiments}

231 Because the field pipeline section is still working, it is necessary to establish the experimental 232 facility.

\subsubsection{Establishing an experimental facility}


234 A laboratory scaled high-pressure gas pipeline loop is established after similarity analyses of field transportation pipelines, as presented in Fig. 4. The internal diameter of the pipeline is $42 \mathrm{~mm}$ and the length is $203.0 \mathrm{~m}$. The leak flow rate is controlled via a valve and the orifice. The low frequency response of the dynamic pressure sensor is $0.5 \mathrm{~Hz}$. In the experiments, the natural gas can be replaced by air.

\subsubsection{Experiments for leak detection and location}

240 When leakage point 2, 3, or 4 leaks, sensor 1 is regarded as the starting sensor and sensor 3 is 241 regarded as the end sensor, between which the distance is $136.2 \mathrm{~m}$. The distances between leakage 242 points 2, 3, 4 and sensor 1 are $40.30 \mathrm{~m}, 88.30 \mathrm{~m}$ and $128.30 \mathrm{~m}$, respectively. When leakage point 1 243 leaks, sensors 1 and 3 are used. However, the location of sensor 1 is then changed, and the distances 244 between sensors 1,3 and leakage point 1 are $12 \mathrm{~m}$ and $136.3 \mathrm{~m}$, respectively. When leakage point 5 245 leaks, sensor 2 is regarded as the starting sensor and sensor 4 is considered the end sensor. The 246 distances between sensors 2, 4 and leakage point 5 are $136.3 \mathrm{~m}$ and $11.7 \mathrm{~m}$, respectively. The 247 sampling rate is $3000 \mathrm{~Hz}$, The temperature is $298 \mathrm{~K}$, and the operation pressures are $390 \mathrm{kPa}, 820$ $248 \mathrm{kPa}$, and $1150 \mathrm{kPa}$.

249 All experiments are conducted using both the traditional and new leak location methods, and the 250 mechanism is presented in Fig. 5.

\section{Results and discussion}

\subsection{Leak detection}

When the leakage signals are used to conclude the ACs, the amplitude attenuates due to the gas absorption and pipe interferences as the wave propagates, which is covered by the increasing noise. Hence, the leakage signals measured by the farthest sensor are completely obscured. Though they are processed by the WT, it is difficult to extract the precise amplitude. Therefore, three sensors are used to conclude the ACs without including the farthest one. This means that when leakage point 1 leaks, as in the test, the waves propagate downstream and sensors 1,2, and 3 are used without sensor 4 , but 
when leakage point 5 leaks, as in the test experiment, the waves propagate upstream and sensors 4,3 ,

260 and 2 are used without sensor 1 . In this case, the sensor that is the farthest from the leakage point will

261 not be used because the amplitude weakens significantly as noise becomes increasingly stronger.

262 Thus, because sensor 4 is the farthest one, sensor 3 is regarded as the end sensor.

263 In the experiments, the smallest leakage orifice is $0.10 \mathrm{~mm}$ and the lowest pressure level is $390 \mathrm{kPa}$.

264 Considering the larger noises, a scale of 6 is applied in the WT method, from which the

265 characteristics are extracted. The threshold value is set at $0.1403 / 0.2286$ and $p_{A 0}$ is set at 0.2286

$266 \mathrm{kPa}$. According to the leak detection results presented in Table 3, it can be concluded that all of the

267 leakages can be detected by both methods.

\section{$268 \quad 3.2$ The location methods}

269 After detecting a leak, the characteristics extracted using the WT method are applied as input

270 variables in the cross-correlation algorithm to calculate the time difference for the traditional method.

271 The propagation velocity of the pressure waves can then be calculated.

272 Regarding the new method, the theoretical ACs are obtained based on equations (14), (15) and (16),

273 and the experimental ACs are obtained through experimental fitting, as presented in Table 4.Table 4

274 indicates that even the flowing velocity is low and $\alpha^{+}$is close to $\alpha^{-}$, the flowing effect must be

275 considered.

276 The leak location error is equal to the ratio of the difference between the calculated and the actual

277 distance to the distance between sensors 1 and 3.

278 The leak location results obtained by the two methods are presented in Table 5.

279 It is determined that the errors using traditional method are small, i.e., most are approximately $0.1 \%$, 280 though the largest is $-0.780 \%$. The errors result from the calculation inaccuracies of time differences 281 and velocity. To reduce these errors, more sensors are necessary to measure additional pressures and 282 temperatures, as they are necessary to calculate a more accurate velocity and ensure data 283 synchronization. 
284 The errors calculated using the theoretical ACs for locating leaks range, for the most part, from $0.1 \%$ to $1 \%$, though the largest error is $2.055 \%$. Conversely, the errors calculated using the experimental ACs for locating leakages arrange from $0.001 \%$ to $0.01 \%$, with the largest error being $0.054 \%$.

Though there are various ways to calculate the location errors generated by ACs, errors associated with theoretical ACs are generally larger.

The errors presented herein result from two factors. (1) There are elbows, valves, and so on through which the amplitudes of the waves attenuate faster than they do through a straight pipeline, but the theoretical ACs are calculated based on a straight pipeline. This means that the amplitude will not strictly obey the same exponential laws. Therefore, to reduce errors, the amplitude attenuation law

When the ACs are calculated via the equations, the parameters are assigned as the mean values of the two ends sensors, though in reality, they vary throughout the total length of the pipeline. Thus, when considering the length of the pipeline, the mean values of the starting and end sensors do not represent the actual condition. Hence, to reduce the errors, more pressure and temperature sensors are necessary to calculate more accurate mean values. The new method actually requires a small percentage of extra sensors in comparison that of the traditional method because the velocity calculation of the traditional method requires more sensors.

The later errors result from the inaccuracy of the amplitude, which, in turn, results from the measurement of the original signals and the limitations of the signal-processing method. The errors are also generated during the fitting process of the experimental data. Therefore, to reduce the errors, the acoustic sensors and the WT method should be improved, both of which are also key factors influencing the data synchronization of the traditional method.

However, the errors of the new method calculated using the experimental ACs are smaller, generally, than the errors obtained using the traditional method. Thus, it is concluded that the new method is effective when the ACs are obtained via experimental fitting or theoretical calculations that use more 
accurate parameters.

310 Conclusions are also drawn from the results of the experiments using $10 \mathrm{~mm}$ pipelines, where the 311 largest location error is $-0.768 \%$ for the traditional method and $-0.669 \%$ for the new method using 312 experimental ACs at $1 \mathrm{MPa}$, as presented in Table 6.

313 To verify the influence of the flowing gas on locating the leak, equation (20), in which the flowing 314 gas is ignored, is applied. The results are presented in Table 7.

315 It is determined that the location errors are large, i.e., approximately $10 \%$.

316 Though the errors exist, the new method is able to detect and locate leakages. The key factors

317 influencing the accuracy are the amplitude extraction and the calculation of ACs, indicating that 318 these factors require greater attention in the future. Thus, it is concluded that the new method, which 319 is based on amplitude, is more promising.

320 When comparing the new location method with the traditional method, it is determined that they 321 have much in common. For example, both need to conduct test experiments to obtain the threshold 322 value for leak detection; both should be adjusted to satisfy the changing operation situations, such as 323 changes in acoustic velocity due to changes in pressure and changes in ACs due to changes in pressure; and both require accuracy with respect to extracted amplitude, the traditional one, which calculates the time difference, and the new one, which directly calculates the location point.

\section{Conclusions}

The following conclusions can be drawn regarding the leak detection and location methods based on the propagation model of waves considering the gas flowing effect in the gas pipeline. (1) All leakages in gas pipelines can be detected by the proposed methods. The largest location error 330 when using the traditional method is $-0.780 \%$. The largest errors when using the new method with 331 the theoretical and experimental ACs are $2.055 \%$ and $0.054 \%$, respectively.

332 (2) When the traditional method is applied, the new method can also be applied. In $42 \mathrm{~mm}$ pipelines, 333 when the experimental ACs are applied, the location errors are smaller than those of the traditional 
method. Considering that the experimental ACs are obtained by the test experiments that are necessary for both methods, from the perspective of time and money, the new method is superior to

the traditional one. If it is difficult to determine the experimental ACs, the calculation of the theoretical ACs may need more sensors to achieve the same precision as the traditional method. The cost of the new method, considering the extra sensors and the excluded devices, should compared with the cost of the traditional method according to actual situations. However, it is difficult to achieve a good synchronization of data for the traditional method, and thus, it may require additional investments. Thus, if location precision is desired, the new method should be the first choice based on conciseness and feasibility.

(3) The new method, which is based on amplitude, is more promising and can provide a new approach to the detection and location of leakages in gas pipelines. Further studies should be conducted to address situations where multiple leakages occur in pipelines.

\section{Acknowledgements}

This paper was funded by the National Science Foundation of China (51104175), (51374231), the Opening Project of Guangxi Colleges and Universities Key Laboratory of Beibu Gulf Oil and Natural Gas Resource Effective Utilization (2014KLOGO1), and the Fundamental Research Funds for the Central Universities (15CX06069A). Thank you for permission to publish this paper.

\section{References}

[1] Murvay P.S., Silea I.. A survey on gas leak detection and localization techniques. Journal of Loss Prevention in the Process Industries, 25(6)(2012): 966-973

[2] Alkhaledi K., Alrushaid S., Almansouri J., et al. Using fault tree analysis in the Al-Ahmadi town gas leak incidents. Safety Science, 79 (2015): 184-192

[3] Elaoud, S., Hadj-Tal, eb, L., \& Hadj-Tal, eb, E.. Leak detection of hydrogen-natural gas mixtures in pipes using the characteristics method of specified time intervals. Journal of Loss Prevention in the Process Industries, 23(5) (2010): 637-645

[4] Scott, S., Barrufet, M.. Worldwide assessment of industry leak detection capabilities for single \& multiphase pipelines. Tech. rep. Dept. of Petroleum Engineering, Texas A\&M University, 2003

[5] Doorhy, J.. Real-time pipeline leak detection and location using volume balancing. Pipeline \& Gas Journal, 238(2) (2011): 65-66.

[6] Zhang T. T., Tan Y. F., Zhang X. D., et al. A novel hybrid technique for leak detection and location in straight pipelines. Journal of Loss Prevention in the Process Industries, 35 (2015): 157-168 
[7] Lee L. H., Rajkumar R., Lo L. H., et al.. Oil and gas pipeline failure prediction system using long range ultrasonic transducers and Euclidean-support vector machines classification approach. Expert Systems with Applications, 40(2013): 1925-1934

[8] Yan R. X., Qi L.. The gas leak detection technology of the spacecraft on orbit based on acoustic sensor array. Physics Procedia, 70 ( 2015): 384-387

[9] Yan L., Yan G., Zhao Q.X.. A median filtering algorithm based on extremum detection. Advanced Materials Research, 889-890 (2014): 1099-1102

[10] Xu P.F., Miao Q.G., Tang X., et al. A denoising algorithm via wiener filtering in the shearlet domain. Multimedia Tools and Applications, 71(3)(2014): 1529-1558

[11] Hu Z.B., Xu M.X., Jiang G.D., et al. Analysis of non-stationary signal of a sudden unbalanced spindle based on wavelet noise reduction and short-time Fourier transformation. Journal of Vibration and Shock, 33(5)(2014): 20-23+36.

[12] A. Mostafapour, S. Davoodi, M. Ghareaghaji. Acoustic emission source location in plates using wavelet analysis and cross time frequency spectrum. Ultrasonics, 54(8)(2014): 2055-2062.

[13] Lu L., Long Y., Zhong M.S., et al. Separating noise from a blasting vibration signal based on fast ICA. Journal of Vibration and Shock, 31(17)(2012): 33-37.

[14] Ni L., Jiang J. C., Pan Y., et al. Leak location of pipelines based on characteristic entropy. Journal of Loss Prevention in the Process Industries, 30(2014): 24-36

[15] Sun J. D., Xiao Q. Y., Wen J. T., et al. Natural gas pipeline leak aperture identification and location based on local mean decomposition analysis. Measurement, 79(2016): 147-157

[16] Liu C. W., Li Y. X., Meng L. Y., et al. Time-frequency analysis of acoustic leakage signal based on hilbert-huang transform for natural gas pipelines. Journal of Vibration and Shock, 33(16)(2014): $42-49$

[17] Ye G., Brennan M.J., Joseph P.F., et al. A model of the correlation function of leak noise in buried plastic pipes. Journal of Sound and Vibration, 277 (2004): 133-148

[18] Brennan M.J., Ye G., Joseph P.F.. On the relationship between time and frequency domain methods in time delay estimation for leak detection in water distribution pipes. Journal of Sound and Vibration, 304 (2007), pp. 213-223

[19] Meng L.Y., Li Y.X., Wang W.C., et al. Experimental study on leak detection and location for gas pipeline based on acoustic method. Journal of Loss Prevention in the Process Industries, 25(1)(2012):90-102

[20] Liu C.W., Li Y.X., Meng L.Y., et al. Study on leak-acoustics generation mechanism for natural gas pipelines. Journal of Loss Prevention in the Process Industries, 32(2014), pp. 174-181

[21] Magnis L. and Petit N.. Impact of measurement dating inaccuracies in the monitoring of bulk flows. Advances in Electrical and Electronic Engineering, 13(1)(2015): 30-38

[22] N. Petit. Analysis of problems induced by imprecise dating of measurements in oil and gas production. Proc. of the ADCHEM 2015, International Symposium on Advanced Control of Chemical Processes, 48(8)(2015): 966-973

[23] Liu C.W., Li Y.X., Fu J.T., et al. Experimental study on acoustic propagation-characteristics-based leak location method for natural gas pipelines. Process Safety and Environmental Protection, 96(2015), pp. 43-60

[24] Hunaidi O., Wing T. C.. Acoustical characteristics of leak signals in Plastic water distribution pipes. Applied Acoustics, 1999, 58(3): 235-254

[25] Muggleton J. M., Brennan M. J., Pinnington R. J.. Wave number prediction of waves in buried pipes for water leak detection. J. Sound Vib., 2002, 249(5): 939-954

[26] Liu J.X., Li T.Y., Liu T.G., et al. The attenuation characteristics of waves in fluid-filled pipes surrounded by elastic media. J. Huazhong Univ. Science and Technology (Nature Science Edition), 31(10)(2003): 90-92

[27] Williams J. E. F., Hawkings D. L.. Sound generation by turbulence and surfaces in arbitrary motion. Philosophical Transactions for the Royal Society of London, Series A, Mathematical and Physical Sciences, 1969, 264(1151):321-342.

[28] Chen K.A., Ceng X.Y., Li H.Y.. Acoustic Measurement; Science Press, Beijing(2005)

[29] Yang J.G.. Wavelet analysis and Engineering Application; Mechanical Industry Press, Beijing(2005)

[30] He L., Zhu H.C., Qiu X.J.. The Acoustics Theory and Engineering Application books. Science Press, Beijing(2006)

[31] Ma D.Y.. Theoretical basis of modern acoustics books. Science Press, Beijing(2004)

[32] Sun X.F., Zhou S.. Aero-acoustics books. National Defense Industry Press, Beijing(1994)

[33] Munjal M. L.. Acoustics of Ducts and Mufflers with application to exhaust and ventilation. Wiley, New York(1987) 
424 The collected table and figure captions

425 Table 1 Evaluation indexes of leak detection and location methods

426 Table 2 Characteristics of WT analyses under different conditions

427 Table 3 Leak detection for $42 \mathrm{~mm}$ gas pipeline

428 Table 4 The attenuation coefficients in $42 \mathrm{~mm}$ pipelines

429 Table 5 Leak location results of two methods in $42 \mathrm{~mm}$ pipelines

430 Table 6 Leak location results of two methods in $10 \mathrm{~mm}$ pipelines

431 Table 7 Leak location results of new method based on equation (20) in $42 \mathrm{~mm}$ pipelines

432 Fig. 1 The diagram of leak detection

433 Fig. 2 The fundamental of leak detection

434 Fig. 3 Propagation principle along the pipeline

435 Fig. 4 Pipeline leak detection and location test loops with $42 \mathrm{~mm}$

436 Fig. 5 The diagram of leak location methods

437

438

439 
Graphical Abstract

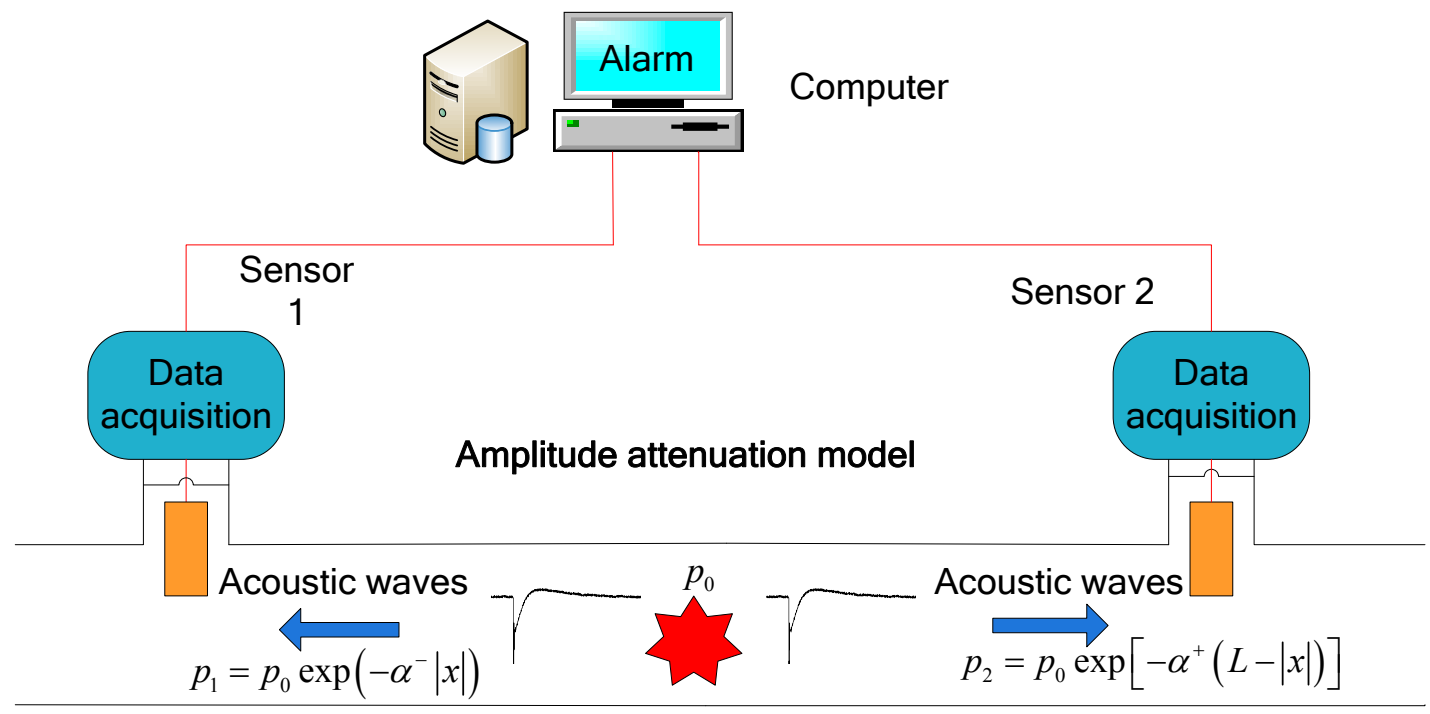

Gas pipeline 
Table 1 Evaluation indexes of leak detection and location methods

\begin{tabular}{|c|c|c|c|c|c|c|c|}
\hline The leak detection method & Sensitivity & $\begin{array}{l}\text { Location } \\
\text { accuracy }\end{array}$ & $\begin{array}{c}\text { False } \\
\text { alarm } \\
\text { rate }\end{array}$ & $\begin{array}{l}\text { Missing alarm } \\
\text { rate }\end{array}$ & $\begin{array}{l}\text { Detection } \\
\text { time }\end{array}$ & Cost & $\begin{array}{l}\text { Total } \\
\text { score }\end{array}$ \\
\hline Fault tree analysis & 1 & 3 & 4 & 2 & 2 & 3 & 15 \\
\hline Negative pressure method & 3 & 4 & 3 & 3 & 3 & 3 & 19 \\
\hline Transient model method & 4 & 4 & 3 & 4 & 3 & 2 & 20 \\
\hline $\begin{array}{l}\text { Mass/volume balance } \\
\text { method }\end{array}$ & 4 & 4 & 3 & 4 & 3 & 3 & 21 \\
\hline Hybrid technique & 4 & 4 & 4 & 3 & 4 & 3 & 22 \\
\hline Acoustic method & 5 & 5 & 3 & 5 & 5 & 3 & 26 \\
\hline $\begin{array}{l}\text { Method based on dynamic } \\
\text { pressure wave }\end{array}$ & 5 & 5 & 4 & 5 & 5 & 3 & 27 \\
\hline
\end{tabular}

Table 2 Characteristics of WT analyses under different conditions

\begin{tabular}{ccccccc}
\hline & \multicolumn{5}{c}{ Amplitude/kPa } \\
\cline { 3 - 7 } $\begin{array}{c}\text { Diameter of } \\
\text { leakage orifice/mm }\end{array}$ & Number & $\begin{array}{c}\text { original signal } \\
\text { measured in Jixian }\end{array}$ & $\begin{array}{c}\text { A4 in } \\
\text { Jixian }\end{array}$ & $\begin{array}{c}\text { A4 by the } \\
\text { other sensor }\end{array}$ & $\begin{array}{c}\text { A4 to original signal } \\
\text { measured in Jixian }\end{array}$ & $\begin{array}{c}\text { A4 by the other } \\
\text { sensor to A8 in } \\
\text { Jixian }\end{array}$ \\
\hline \multirow{2}{*}{10} & 1 & 0.2300 & 0.1574 & 0.0953 & 68.45 & 60.52 \\
& 2 & 0.2250 & 0.1548 & 0.0935 & 68.79 & 60.38 \\
7 & 1 & 0.2200 & 0.1516 & 0.0919 & 68.91 & 60.60 \\
& 2 & 0.2160 & 0.1485 & 0.0898 & 68.75 & 60.49 \\
5 & 1 & 0.2090 & 0.1436 & 0.0867 & 68.69 & 60.42 \\
& 2 & 0.2000 & 0.1378 & 0.0831 & 68.88 & 60.29 \\
\hline
\end{tabular}

Table 3 Leak detection for $42 \mathrm{~mm}$ gas pipeline

\begin{tabular}{|c|c|c|c|c|c|c|c|c|}
\hline \multirow{2}{*}{ Leakage point } & \multirow{2}{*}{$\begin{array}{c}\text { Operating } \\
\text { pressure/MPa }\end{array}$} & \multirow{2}{*}{$\begin{array}{c}\text { Leakage } \\
\text { orifice/mm }\end{array}$} & \multicolumn{2}{|c|}{$p_{A 0} / \mathrm{kPa}$} & \multicolumn{2}{|c|}{ Amplitude of WT signal $/ \mathrm{kPa}$} & \multirow{2}{*}{$\begin{array}{l}\text { Leakage or not } \\
\text { (judged by } \\
\text { experiment) }\end{array}$} & \multirow{2}{*}{$\begin{array}{c}\text { Leakage or not } \\
\text { (judged by } \\
\text { simulation) }\end{array}$} \\
\hline & & & Experiment & Simulation & n Starting sensor & End sensor & & \\
\hline \multirow{9}{*}{ Point 1} & & 0.1 & \multirow{9}{*}{-0.2286} & \multirow{9}{*}{-0.1985} & -0.2187 & -0.1668 & Yes & Yes \\
\hline & 0.4 & 0.5 & & & -0.1922 & -0.1466 & Yes & Yes \\
\hline & & 1.0 & & & -0.3091 & -0.2359 & Yes & Yes \\
\hline & & 0.1 & & & -0.4308 & -0.3730 & Yes & Yes \\
\hline & 0.8 & 0.5 & & & -0.3976 & -0.3443 & Yes & Yes \\
\hline & & 1.0 & & & -0.5781 & -0.5005 & Yes & Yes \\
\hline & \multirow{3}{*}{1.2} & 0.1 & & & -0.6887 & -0.6033 & Yes & Yes \\
\hline & & 0.5 & & & -0.6385 & -0.5593 & Yes & Yes \\
\hline & & 1.0 & & & -0.8243 & -0.7220 & Yes & Yes \\
\hline
\end{tabular}




\begin{tabular}{|c|c|c|c|c|c|c|}
\hline \multirow{9}{*}{ Point 2} & \multirow{3}{*}{0.4} & 0.1 & -0.1970 & -0.1832 & Yes & Yes \\
\hline & & 0.5 & -0.1731 & -0.161 & Yes & Yes \\
\hline & & 1.0 & -0.2785 & -0.2589 & Yes & Yes \\
\hline & \multirow{3}{*}{0.8} & 0.1 & -0.4098 & -0.3917 & Yes & Yes \\
\hline & & 0.5 & -0.3782 & -0.3616 & Yes & Yes \\
\hline & & 1.0 & -0.5499 & -0.5257 & Yes & Yes \\
\hline & \multirow{3}{*}{1.2} & 0.1 & -0.6580 & -0.6311 & Yes & Yes \\
\hline & & 0.5 & -0.6100 & -0.5851 & Yes & Yes \\
\hline & & 1.0 & -0.7875 & -0.7553 & Yes & Yes \\
\hline \multirow{9}{*}{ Point 3} & \multirow{3}{*}{0.4} & 0.1 & -0.1650 & -0.2046 & Yes & Yes \\
\hline & & 0.5 & -0.1450 & -0.1799 & Yes & Yes \\
\hline & & 1.0 & -0.2333 & -0.2893 & Yes & Yes \\
\hline & \multirow{3}{*}{0.8} & 0.1 & -0.3765 & -0.4152 & Yes & Yes \\
\hline & & 0.5 & -0.3475 & -0.3832 & Yes & Yes \\
\hline & & 1.0 & -0.5052 & -0.5572 & Yes & Yes \\
\hline & \multirow{3}{*}{1.2} & 0.1 & -0.6089 & -0.6658 & Yes & Yes \\
\hline & & 0.5 & -0.5645 & -0.6173 & Yes & Yes \\
\hline & & 1.0 & -0.7287 & -0.7968 & Yes & Yes \\
\hline \multirow{9}{*}{ Point 4} & \multirow{3}{*}{0.4} & 0.1 & -0.1424 & -0.2244 & Yes & Yes \\
\hline & & 0.5 & -0.1251 & -0.1973 & Yes & Yes \\
\hline & & 1.0 & -0.2013 & -0.3173 & Yes & Yes \\
\hline & \multirow{3}{*}{0.8} & 0.1 & -0.3508 & -0.4359 & Yes & Yes \\
\hline & & 0.5 & -0.3237 & -0.4023 & Yes & Yes \\
\hline & & 1.0 & -0.4707 & -0.5849 & Yes & Yes \\
\hline & \multirow{3}{*}{1.2} & 0.1 & -0.5708 & -0.6961 & Yes & Yes \\
\hline & & 0.5 & -0.5292 & -0.6453 & Yes & Yes \\
\hline & & 1.0 & -0.6831 & -0.8331 & Yes & Yes \\
\hline \multirow{9}{*}{ Point 5} & \multirow{3}{*}{0.4} & 0.1 & -0.1382 & -0.2225 & Yes & Yes \\
\hline & & 0.5 & -0.1215 & -0.1955 & Yes & Yes \\
\hline & & 1.0 & -0.1954 & -0.3145 & Yes & Yes \\
\hline & \multirow{3}{*}{0.8} & 0.1 & -0.3458 & -0.4339 & Yes & Yes \\
\hline & & 0.5 & -0.3192 & -0.4004 & Yes & Yes \\
\hline & & 1.0 & -0.4641 & -0.5822 & Yes & Yes \\
\hline & \multirow{3}{*}{1.2} & 0.1 & -0.5635 & -0.6931 & Yes & Yes \\
\hline & & 0.5 & -0.5224 & -0.6426 & Yes & Yes \\
\hline & & 1.0 & -0.6744 & -0.8295 & Yes & Yes \\
\hline
\end{tabular}


Table 4 The attenuation coefficients in $42 \mathrm{~mm}$ pipelines

\begin{tabular}{|c|c|c|c|c|c|c|c|c|}
\hline Temperature/K & $\begin{array}{c}\text { Operating } \\
\text { K pressure } \\
/ \mathrm{kPa}\end{array}$ & $\begin{array}{l}\text { Center } \\
\text { frequency/Hz }\end{array}$ & $\begin{array}{l}\text { Gas velocity } \\
\text { in positive } \\
\text { z flowing } \\
\text { direction } / \mathrm{m} / \mathrm{s}\end{array}$ & $\begin{array}{l}\text { Gas velocity } \\
\text { in positive } \\
\text { flowing } \\
\text { direction } / \mathrm{m} / \mathrm{s}\end{array}$ & $\begin{array}{c}\alpha^{+} \\
\text {calculated } \\
\text { by } \\
\text { equation }\end{array}$ & $\begin{array}{c}\alpha^{-} \\
\text {calculated } \\
\text { by } \\
\text { equation }\end{array}$ & $\begin{array}{c}\alpha^{+} \\
\text {obtained } \\
\text { through } \\
\text { experiments }\end{array}$ & $\begin{array}{c}\alpha^{-} \\
\text {obtained } \\
\text { through } \\
\text { experiments }\end{array}$ \\
\hline 298 & 390 & 11.71875 & 0.565 & 1.845 & 0.002243 & 0.003582 & 0.002310 & 0.003690 \\
\hline 298 & 820 & 11.71875 & 0.031 & 0.451 & 0.001189 & 0.001741 & 0.001213 & 0.001768 \\
\hline 298 & 1150 & 11.71875 & 0.139 & 0.602 & 0.001074 & 0.001556 & 0.001114 & 0.001615 \\
\hline
\end{tabular}

Table 5 Leak location results of two methods in $42 \mathrm{~mm}$ pipelines

\begin{tabular}{|c|c|c|c|c|c|c|c|c|}
\hline \multirow{3}{*}{$\begin{array}{c}\text { Leakage } \\
\text { point }\end{array}$} & \multirow{3}{*}{$\begin{array}{c}\text { Operating } \\
\text { pressure } \\
/ \mathrm{kPa}\end{array}$} & \multirow{3}{*}{$\begin{array}{c}\text { Leakage } \\
\text { orifice } \\
/ \mathrm{mm}\end{array}$} & \multicolumn{2}{|c|}{ Traditional method } & \multicolumn{4}{|c|}{ New method based on equation (19) } \\
\hline & & & \multirow{2}{*}{$\begin{array}{l}\text { Location } \\
\text { point/m }\end{array}$} & \multirow[b]{2}{*}{$\begin{array}{l}\text { Location } \\
\text { error/\% }\end{array}$} & \multicolumn{2}{|c|}{ ACs obtained by experiments } & \multicolumn{2}{|c|}{ ACs calculated by equation } \\
\hline & & & & & $\begin{array}{l}\text { Location } \\
\text { point/m }\end{array}$ & $\begin{array}{l}\text { Location } \\
\text { error } \%\end{array}$ & $\begin{array}{l}\text { Location } \\
\text { point/m }\end{array}$ & $\begin{array}{l}\text { Location } \\
\text { error/\% }\end{array}$ \\
\hline \multirow{9}{*}{ Point 1} & \multirow{3}{*}{390} & 0.1 & 12.303 & 0.204 & 11.977 & -0.016 & 10.631 & -0.923 \\
\hline & & 0.5 & 11.784 & -0.146 & 12.003 & 0.002 & 10.657 & -0.905 \\
\hline & & 1.0 & 12.311 & 0.210 & 12.023 & 0.016 & 10.679 & -0.891 \\
\hline & \multirow{3}{*}{820} & 0.1 & 12.406 & 0.274 & 12.025 & 0.017 & 11.019 & -0.661 \\
\hline & & 0.5 & 12.511 & 0.345 & 12.033 & 0.022 & 11.027 & -0.656 \\
\hline & & 1.0 & 12.304 & 0.205 & 12.011 & 0.007 & 11.005 & -0.671 \\
\hline & \multirow{3}{*}{1150} & 0.1 & 11.845 & -0.105 & 12.012 & 0.008 & 10.209 & -1.208 \\
\hline & & 0.5 & 11.798 & -0.136 & 12.011 & 0.008 & 10.208 & -1.208 \\
\hline & & 1.0 & 12.411 & 0.277 & 11.995 & -0.003 & 10.191 & -1.220 \\
\hline \multirow{9}{*}{ Point 2} & \multirow{3}{*}{390} & 0.1 & 39.720 & -0.426 & 40.333 & 0.024 & 39.978 & -0.236 \\
\hline & & 0.5 & 39.509 & -0.580 & 40.359 & 0.044 & 40.005 & -0.216 \\
\hline & & 1.0 & 39.920 & -0.279 & 40.274 & -0.019 & 39.918 & -0.281 \\
\hline & \multirow{3}{*}{820} & 0.1 & 39.710 & -0.433 & 40.268 & -0.024 & 39.853 & -0.328 \\
\hline & & 0.5 & 39.720 & -0.426 & 40.364 & 0.047 & 39.951 & -0.256 \\
\hline & & 1.0 & 39.509 & -0.580 & 40.324 & 0.017 & 39.910 & -0.286 \\
\hline & \multirow{3}{*}{1150} & 0.1 & 39.590 & -0.522 & 40.303 & 0.002 & 39.748 & -0.405 \\
\hline & & 0.5 & 40.160 & -0.103 & 40.326 & 0.019 & 39.773 & -0.387 \\
\hline & & 1.0 & 40.270 & -0.022 & 40.300 & 0.000 & 39.745 & -0.407 \\
\hline \multirow{7}{*}{ Point 3} & \multirow{3}{*}{390} & 0.1 & 87.868 & -0.317 & 88.289 & -0.008 & 89.375 & 0.789 \\
\hline & & 0.5 & 87.868 & -0.317 & 88.382 & 0.060 & 89.470 & 0.859 \\
\hline & & 1.0 & 87.788 & -0.376 & 88.294 & -0.005 & 89.380 & 0.793 \\
\hline & \multirow{3}{*}{820} & 0.1 & 87.588 & -0.523 & 88.243 & -0.042 & 88.664 & 0.267 \\
\hline & & 0.5 & 87.868 & -0.317 & 88.226 & -0.054 & 88.646 & 0.254 \\
\hline & & 1.0 & 87.868 & -0.317 & 88.286 & -0.010 & 88.707 & 0.299 \\
\hline & 1150 & 0.1 & 88.649 & 0.256 & 88.333 & 0.025 & 89.587 & 0.945 \\
\hline
\end{tabular}




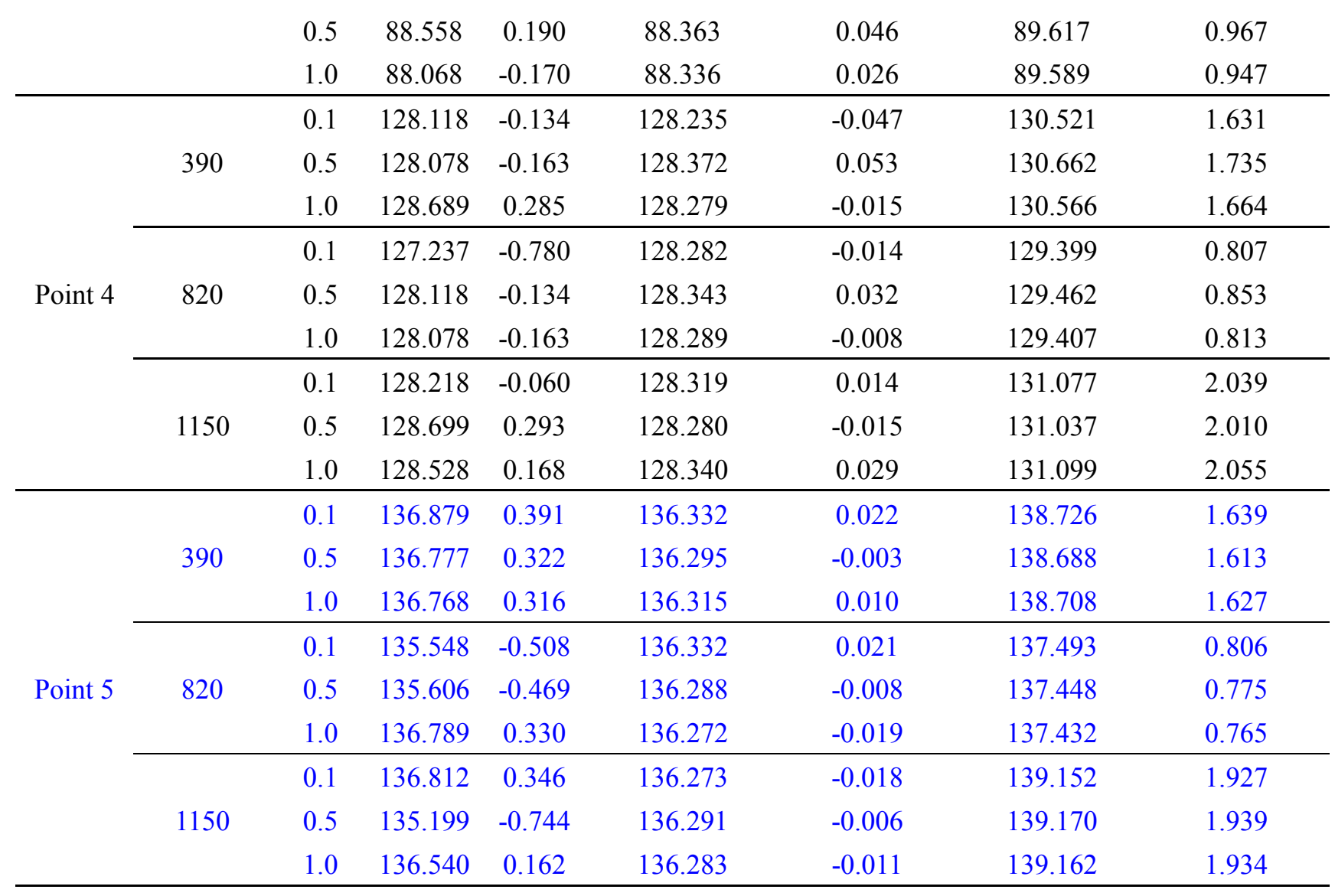

Table 6 Leak location results of two methods in $10 \mathrm{~mm}$ pipelines

\begin{tabular}{|c|c|c|c|c|c|c|c|}
\hline \multirow{2}{*}{$\begin{array}{l}\text { Pressure } \\
/ \mathrm{MPa}\end{array}$} & \multirow{2}{*}{$\begin{array}{c}\text { Leakage } \\
\text { orifice } \\
/ \mathrm{mm} \\
\end{array}$} & \multirow{2}{*}{$\begin{array}{c}\text { Number of } \\
\text { sensors }\end{array}$} & \multirow{2}{*}{$\begin{array}{c}\text { Actual } \\
\text { distance } \\
\text { /m }\end{array}$} & \multicolumn{2}{|c|}{ Traditional method } & \multicolumn{2}{|c|}{ New method with experimental ACs } \\
\hline & & & & $\begin{array}{c}\text { Location } \\
\text { point/m }\end{array}$ & $\begin{array}{l}\text { Location } \\
\text { error/\% }\end{array}$ & $\begin{array}{c}\text { Location } \\
\text { point } / \mathrm{m}\end{array}$ & $\begin{array}{c}\text { Location } \\
\text { error/\% }\end{array}$ \\
\hline \multirow{12}{*}{1} & \multirow{4}{*}{0.1} & 2 & & & & & \\
\hline & & 3 & 48.20 & 48.169 & 0.350 & 47.929 & -0.148 \\
\hline & & 4 & 109.00 & 47.988 & -0.011 & 47.415 & -0.537 \\
\hline & & 5 & 160.39 & 47.281 & -0.448 & 46.927 & -0.669 \\
\hline & \multirow{4}{*}{0.45} & 2 & & & & & \\
\hline & & 3 & 48.20 & 48.169 & 0.350 & 48.112 & 0.232 \\
\hline & & 4 & 109.00 & 48.159 & 0.146 & 48.011 & 0.010 \\
\hline & & 5 & 160.39 & 46.768 & -0.768 & 47.395 & -0.377 \\
\hline & \multirow{4}{*}{0.9} & 2 & & & & & \\
\hline & & 3 & 48.20 & 48.340 & 0.705 & 47.741 & -0.537 \\
\hline & & 4 & 109.00 & 47.988 & -0.011 & 48.023 & 0.021 \\
\hline & & 5 & 160.39 & 10.516 & -23.371 & 47.860 & -0.087 \\
\hline
\end{tabular}


Table 7 Leak location results of new method based on equation (20) in $42 \mathrm{~mm}$ pipelines

\begin{tabular}{|c|c|c|c|c|c|c|}
\hline \multirow{3}{*}{$\begin{array}{c}\text { Leakage } \\
\text { point }\end{array}$} & \multirow{3}{*}{$\begin{array}{c}\text { Operating } \\
\text { pressure } / \mathrm{kPa}\end{array}$} & \multirow{3}{*}{$\begin{array}{c}\text { Leakage } \\
\text { orifice/mm }\end{array}$} & \multicolumn{4}{|c|}{ New location method based on equation (20) } \\
\hline & & & \multicolumn{2}{|c|}{$\begin{array}{l}\text { Attenuation coefficients } \\
\text { obtained by experiments }\end{array}$} & \multicolumn{2}{|c|}{$\begin{array}{c}\text { Attenuation coefficients calculated } \\
\text { by equation }\end{array}$} \\
\hline & & & $\begin{array}{l}\text { Location point } \\
\qquad / \mathrm{m}\end{array}$ & $\begin{array}{l}\text { Location error } \\
\qquad / \%\end{array}$ & $\begin{array}{l}\text { Location point } \\
\qquad / \mathrm{m}\end{array}$ & $\begin{array}{l}\text { Location error } \\
\qquad / \%\end{array}$ \\
\hline \multirow{9}{*}{ Point 1} & \multirow{3}{*}{390} & 0.1 & 28.878 & 11.381 & 27.523 & 10.467 \\
\hline & & 0.5 & 28.891 & 11.390 & 27.536 & 10.476 \\
\hline & & 1.0 & 28.987 & 11.454 & 27.634 & 10.542 \\
\hline & \multirow{3}{*}{820} & 0.1 & 25.773 & 9.288 & 24.947 & 8.730 \\
\hline & & 0.5 & 25.818 & 9.318 & 24.993 & 8.761 \\
\hline & & 1.0 & 25.749 & 9.271 & 24.922 & 8.713 \\
\hline & \multirow{3}{*}{1150} & 0.1 & 25.584 & 9.160 & 23.773 & 7.939 \\
\hline & & 0.5 & 25.568 & 9.149 & 23.756 & 7.927 \\
\hline & & 1.0 & 25.541 & 9.131 & 23.728 & 7.908 \\
\hline \multirow{9}{*}{ Point 2} & \multirow{3}{*}{390} & 0.1 & 55.963 & 11.500 & 55.600 & 11.233 \\
\hline & & 0.5 & 55.990 & 11.520 & 55.628 & 11.254 \\
\hline & & 1.0 & 55.905 & 11.457 & 55.540 & 11.189 \\
\hline & \multirow{3}{*}{820} & 0.1 & 52.931 & 9.274 & 52.672 & 9.084 \\
\hline & & 0.5 & 53.028 & 9.345 & 52.771 & 9.156 \\
\hline & & 1.0 & 52.987 & 9.315 & 52.729 & 9.126 \\
\hline & \multirow{3}{*}{1150} & 0.1 & 52.788 & 9.169 & 52.217 & 8.750 \\
\hline & & 0.5 & 52.812 & 9.186 & 52.241 & 8.768 \\
\hline & & 1.0 & 52.785 & 9.167 & 52.214 & 8.747 \\
\hline \multirow{9}{*}{ Point 3} & \multirow{3}{*}{390} & 0.1 & 104.048 & 11.562 & 105.124 & 12.353 \\
\hline & & 0.5 & 104.141 & 11.630 & 105.220 & 12.423 \\
\hline & & 1.0 & 104.052 & 11.566 & 105.129 & 12.356 \\
\hline & \multirow{3}{*}{820} & 0.1 & 100.955 & 9.292 & 101.516 & 9.703 \\
\hline & & 0.5 & 100.938 & 9.279 & 101.499 & 9.691 \\
\hline & & 1.0 & 100.998 & 9.323 & 101.560 & 9.735 \\
\hline & \multirow{3}{*}{1150} & 0.1 & 100.872 & 9.230 & 102.094 & 10.127 \\
\hline & & 0.5 & 100.901 & 9.252 & 102.124 & 10.150 \\
\hline & & 1.0 & 100.874 & 9.232 & 102.096 & 10.129 \\
\hline \multirow{8}{*}{ Point 4} & \multirow{3}{*}{390} & 0.1 & 144.101 & 11.601 & 146.377 & 13.272 \\
\hline & & 0.5 & 144.238 & 11.702 & 146.519 & 13.376 \\
\hline & & 1.0 & 144.145 & 11.633 & 146.422 & 13.306 \\
\hline & \multirow{3}{*}{820} & 0.1 & 141.034 & 9.349 & 142.279 & 10.264 \\
\hline & & 0.5 & 141.096 & 9.395 & 142.342 & 10.310 \\
\hline & & 1.0 & 141.042 & 9.355 & 142.287 & 10.270 \\
\hline & \multirow{2}{*}{1150} & 0.1 & 140.901 & 9.252 & 143.615 & 11.245 \\
\hline & & 0.5 & 140.862 & 9.223 & 143.575 & 11.215 \\
\hline
\end{tabular}




\begin{tabular}{ccccccc} 
& & 1.0 & 140.922 & 9.267 & 143.637 & 11.261 \\
\cline { 3 - 7 } & \multirow{3}{*}{390} & 0.1 & 153.583 & 11.678 & 155.966 & 13.288 \\
& 0.5 & 153.486 & 11.612 & 155.867 & 13.221 \\
\cline { 3 - 7 } Point 5 & 1.0 & 153.535 & 11.645 & 155.917 & 13.254 \\
\cline { 3 - 7 } & \multirow{2}{*}{820} & 0.1 & 150.210 & 9.399 & 151.511 & 10.278 \\
& & 0.5 & 150.107 & 9.329 & 151.406 & 10.207 \\
& & 1.0 & 150.130 & 9.344 & 151.430 & 10.223 \\
\hline \multirow{2}{*}{1150} & 0.1 & 149.938 & 9.215 & 152.770 & 11.128 \\
& & 0.5 & 149.968 & 9.235 & 152.801 & 11.149 \\
& & 1.0 & 149.935 & 9.213 & 152.767 & 11.126 \\
\hline
\end{tabular}




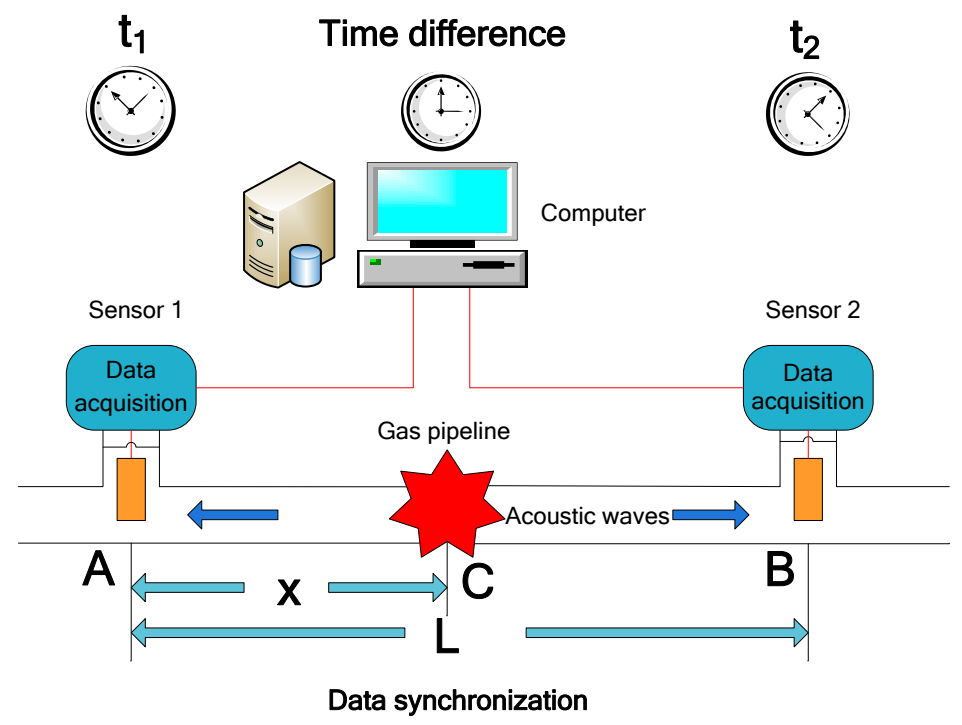

Fig. 1 Diagram of leak detection

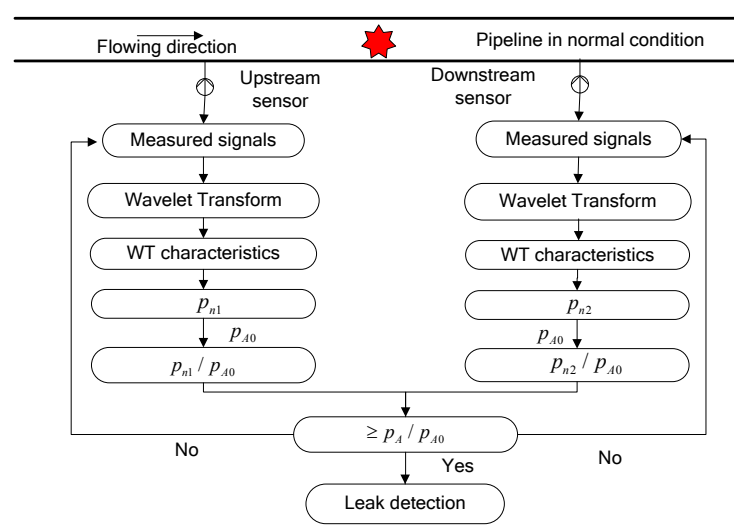

(a) process to detect leaks

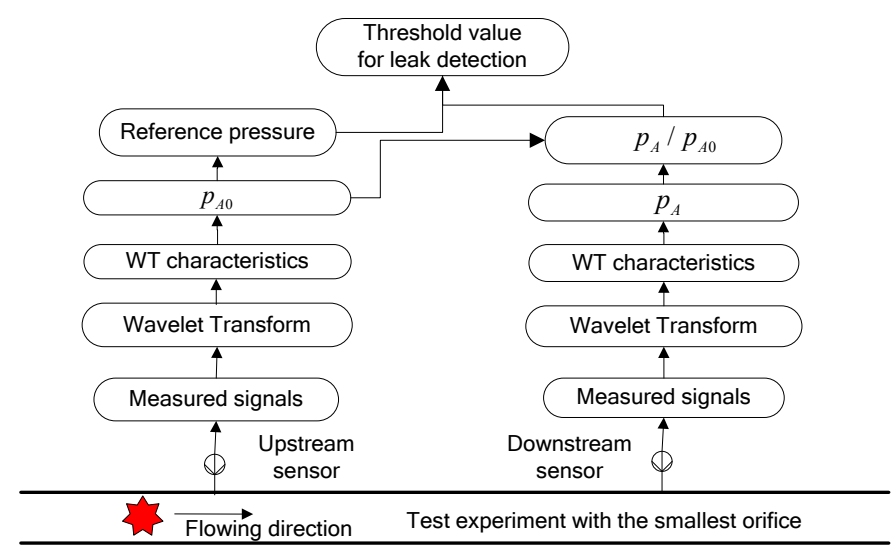

(b) process to determine threshold values

Fig. 2 The fundamental of leak detection 


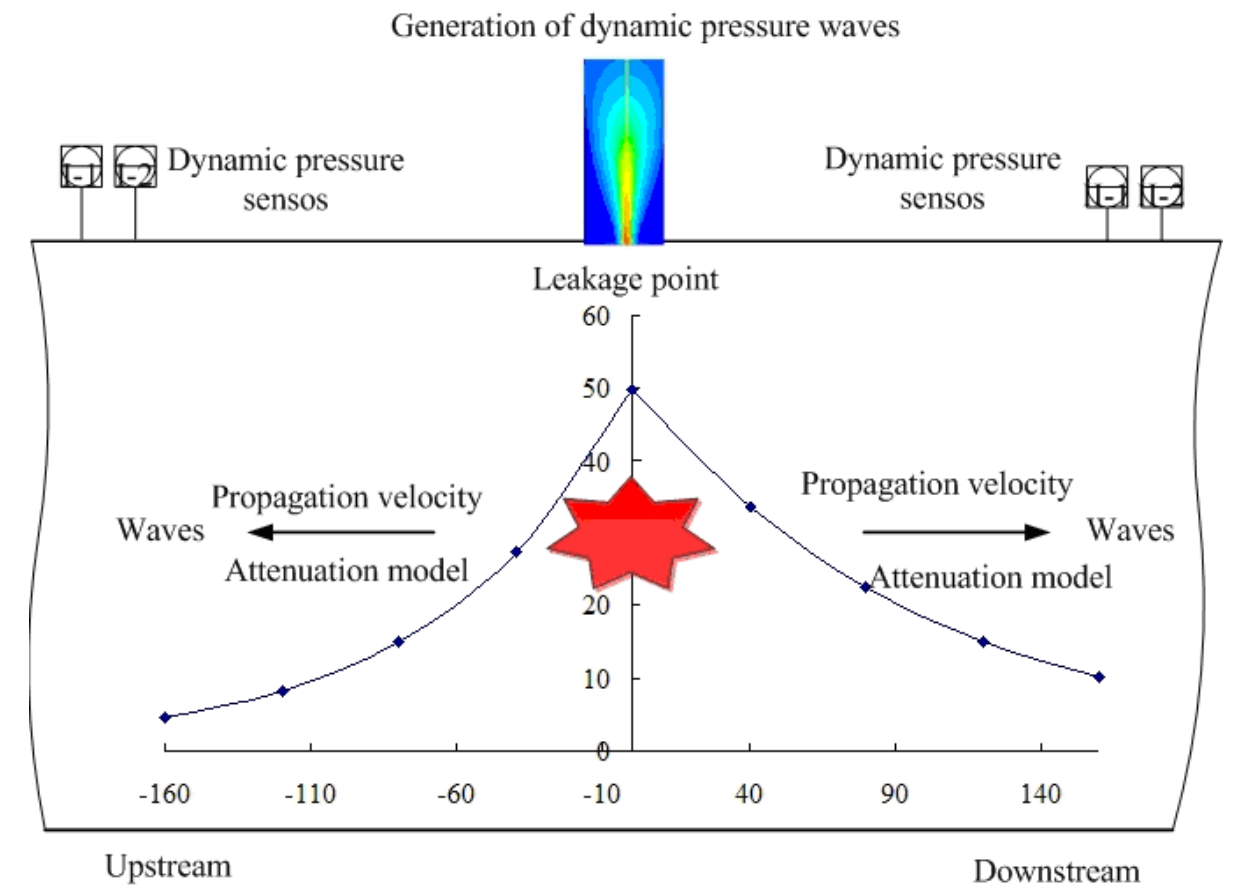

Fig. 3 Propagation principle along the pipeline

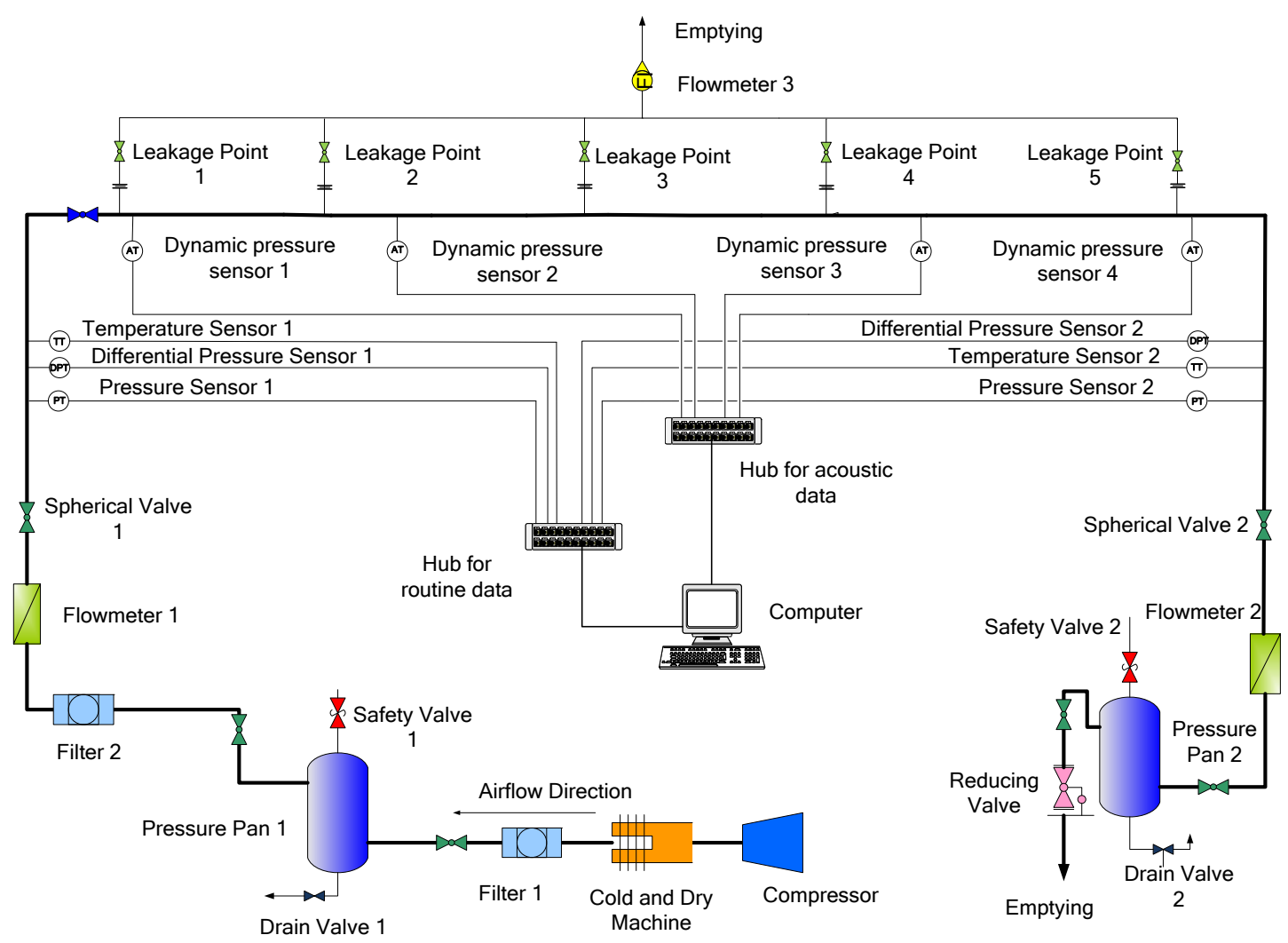

Fig. 4 Pipeline leak detection and location test loops with $42 \mathrm{~mm}$ 


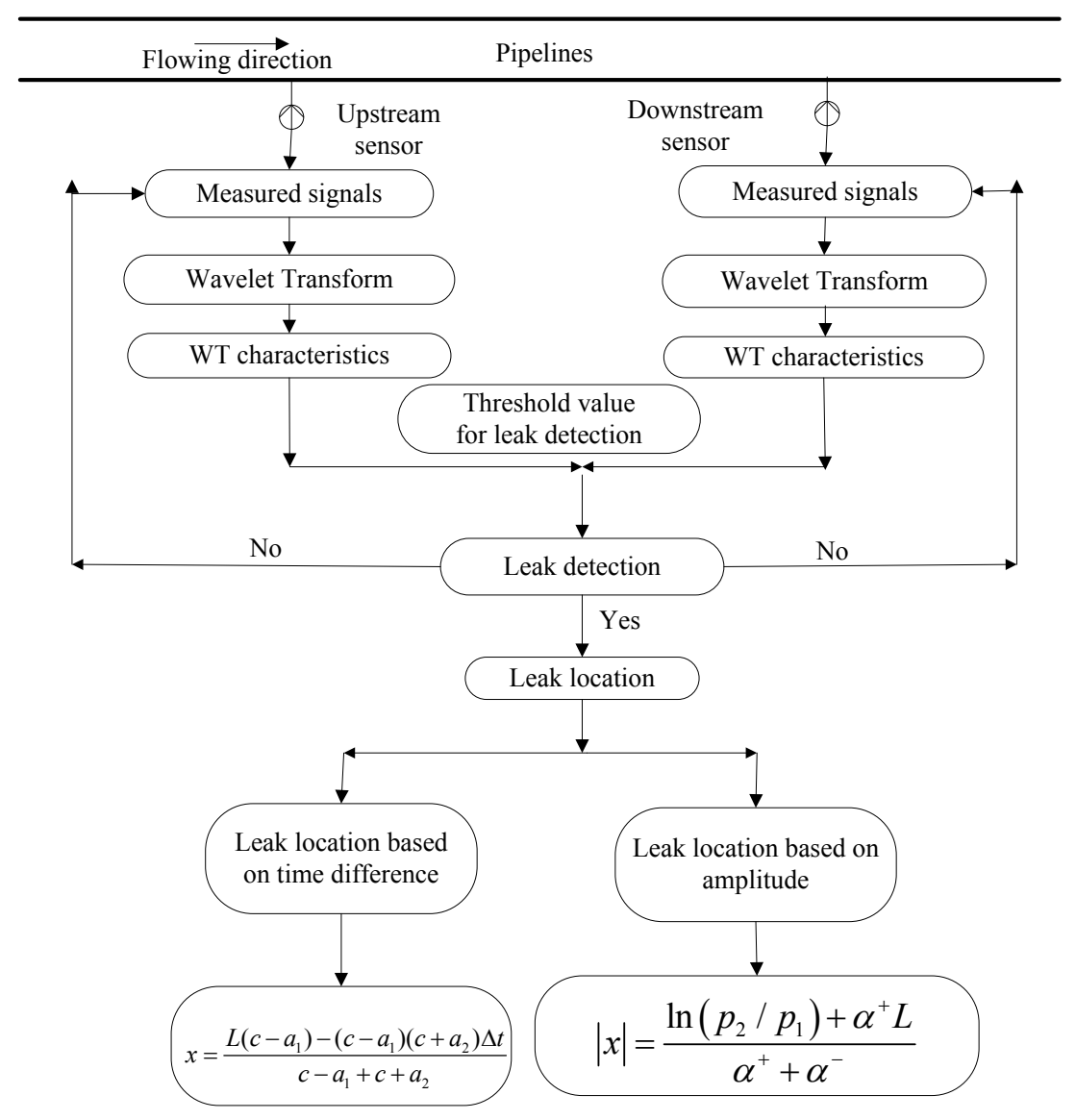

Fig. 5 Diagram of leak location methods 